\title{
The First Local Lockdown
}

\section{Anthon Dixon, Kate Bowers, Nick Tilley, Graham Farrell}

A 'local lockdown' was introduced in Leicester city on 29 June: the city had $<1 \%$ of the UK population but $10 \%$ of all positive COVID-19 cases the week before. We examine recorded crime in July, the first month.

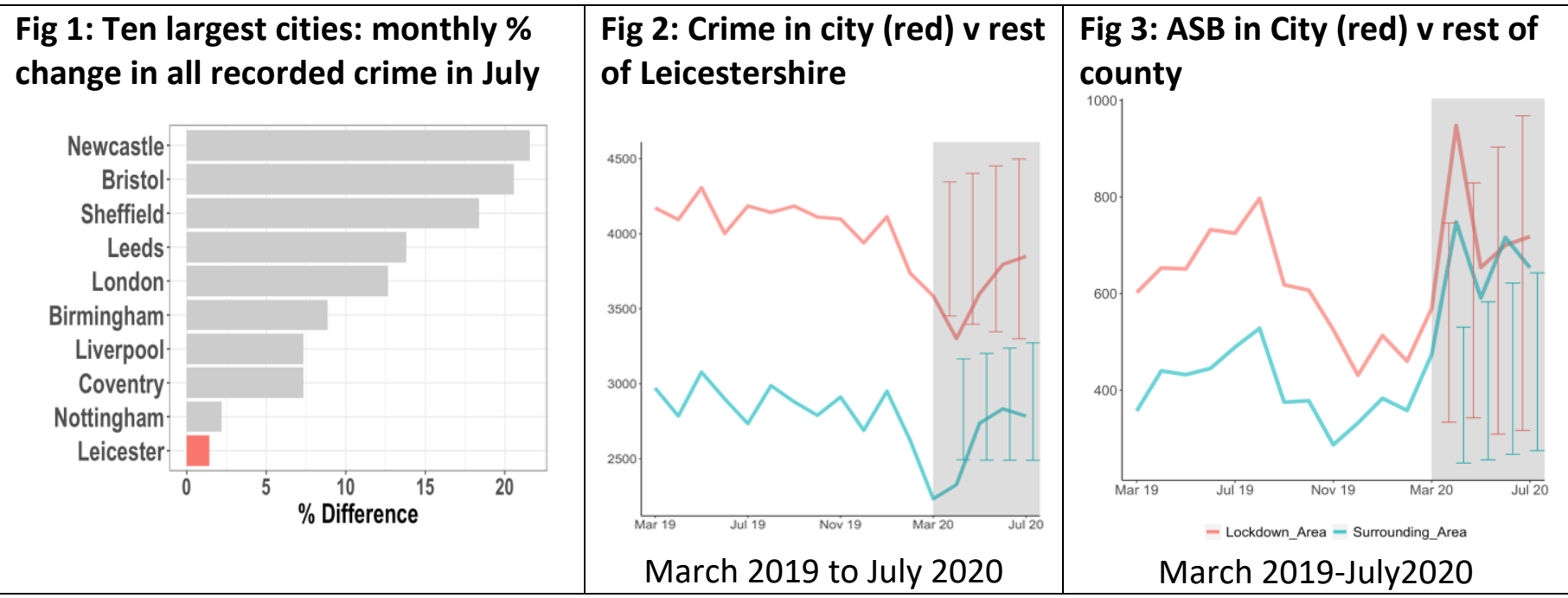

Fig 4: Crime types previously decreasing nationally in lockdown (\% change in July on June)
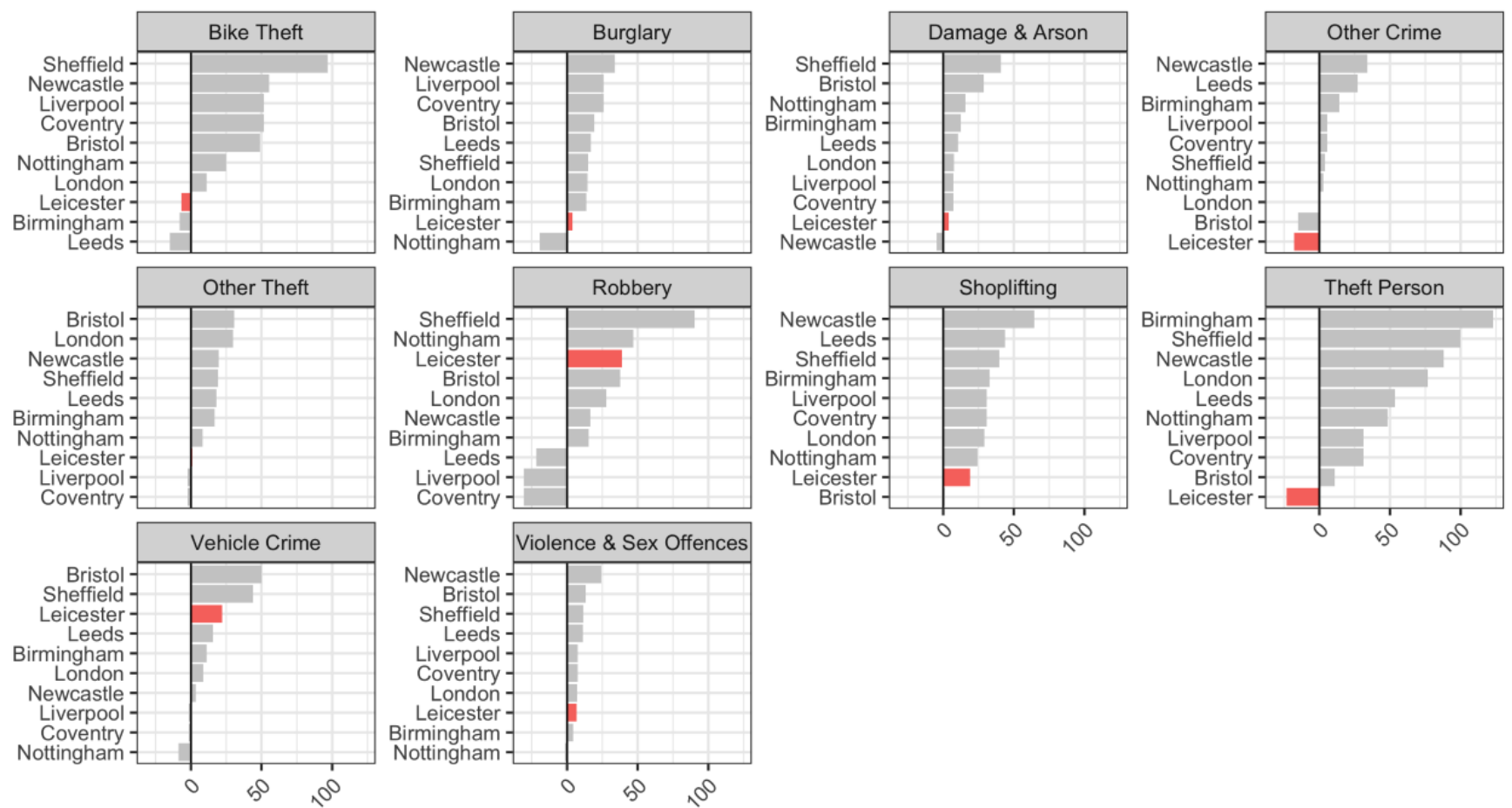

\section{Preliminary Findings}

Fig 1 shows the most populous 10 cities in England and Wales. In July, total recorded crime increased more in cities other than Leicester. Figs 2 and $\mathbf{3}$ shows total recorded crime and ASB increased in the city but declined in the remainder of the county of Leicestershire. Fig 4 shows differences in shoplifting and other theft were most apparent. Fig 5 shows weapons offences decreased in most cities including Leicester. Fig 6 suggests no immediately discernible pattern in the proportion of Leicestershire's crime in the city in July 2020 relative to previous months in the year 
UNIVERSITY OF LEEDS

28 August 2020

STATISTICAL BULLETIN ON CRIME AND COVID-19

Issue 7

Fig 5: Crimes and ASB previously increasing nationally in lockdown (\% change in July on June)
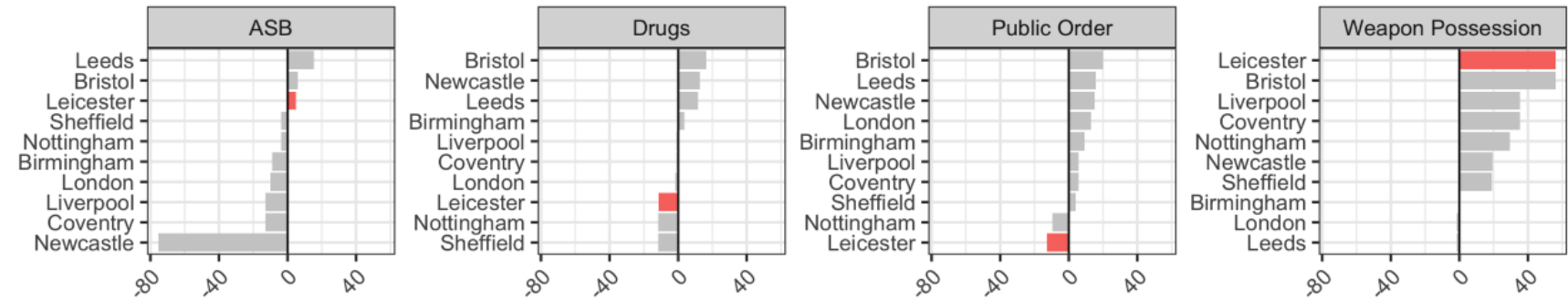

Fig 6: Proportion of Crime in Leicester city (red) versus remainder of Leicestershire (blue) Jan-July 2020
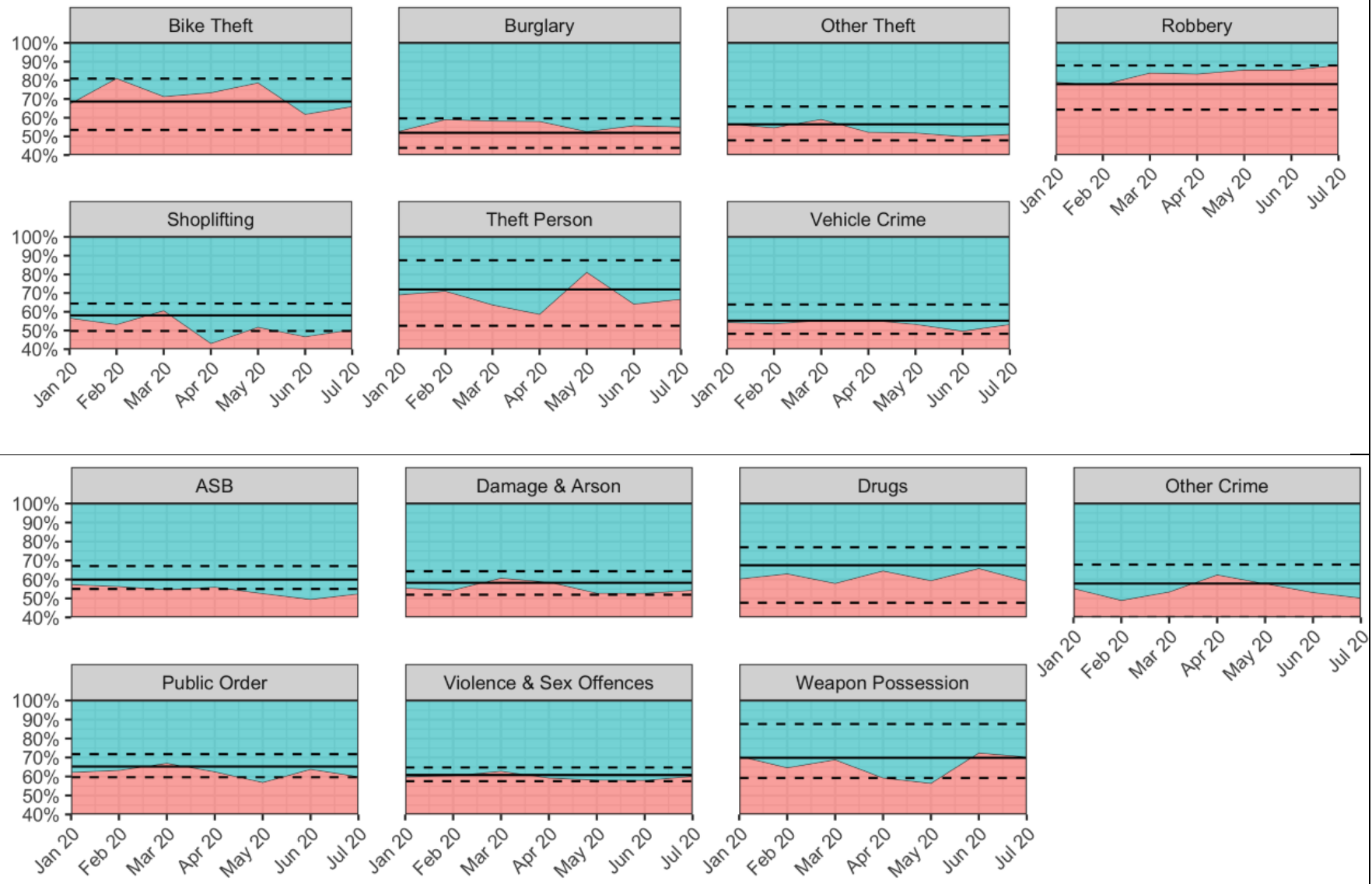

Sources: World Population Review, data.police.uk.

Reference as: Dixon, A., K. J. Bowers, N. Tilley and G. Farrell. (2020). The First Local Lockdown, Statistical Bulletin on Crime and COVID-19, Issue 7. Leeds: University of Leeds.

(C) The Authors (2020). DOI: http://doi.org/10.5518/100/31. ISSN: 2634-4424. This work is licensed under a Creative Commons (CC-BY 4.0). This research was funded by the Economic and Social Research Council under the UK Research and Innovation open call on COVID-19, grant ES/V00445X/1. 